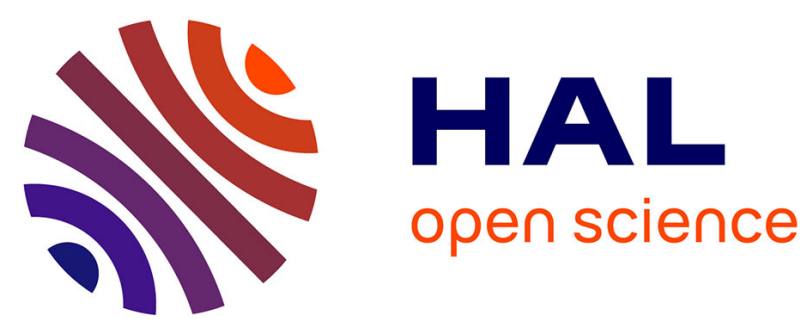

\title{
Effects of Cyclic Fatty Acid Monomers from Heated Vegetable Oil on Markers of Inflammation and Oxidative Stress in Male Wistar Rats
}

Jean Mboma, Nadine Leblanc, Paul Angers, Amandine Rocher, Claire Vigor, Camille Oger, Guillaume Reversat, Joseph Vercauteren, Jean Marie Galano, Thierry Durand, et al.

\section{To cite this version:}

Jean Mboma, Nadine Leblanc, Paul Angers, Amandine Rocher, Claire Vigor, et al.. Effects of Cyclic Fatty Acid Monomers from Heated Vegetable Oil on Markers of Inflammation and Oxidative Stress in Male Wistar Rats. Journal of Agricultural and Food Chemistry, 2018, 66 (27), pp.7172-7180. 10.1021/acs.jafc.8b01836 . hal-02613398

\section{HAL Id: hal-02613398 \\ https://hal.umontpellier.fr/hal-02613398}

Submitted on 3 Jun 2021

HAL is a multi-disciplinary open access archive for the deposit and dissemination of scientific research documents, whether they are published or not. The documents may come from teaching and research institutions in France or abroad, or from public or private research centers.
L'archive ouverte pluridisciplinaire HAL, est destinée au dépôt et à la diffusion de documents scientifiques de niveau recherche, publiés ou non, émanant des établissements d'enseignement et de recherche français ou étrangers, des laboratoires publics ou privés. 


\title{
Effects of Cyclic Fatty Acid Monomers from Heated Vegetable Oil on Markers of Inflammation and Oxidative Stress in Male Wistar Rats
}

\author{
Jean Mboma, ${ }^{\dagger}$ N Nadine Leblanc, ${ }^{\dagger, \S}$ Paul Angers, ${ }^{\ddagger, \S}$ Amandine Rocher, Claire Vigor, $"$ Camille Oger, ${ }^{\| \odot}$ \\ Guillaume Reversat," Joseph Vercauteren," Jean Marie Galano," Thierry Durand," \\ and Hélène Jacques $*, \uparrow, \S$ \\ ${ }^{\dagger}$ School of Nutrition, and ${ }^{\ddagger}$ Department of Food Science, Laval University, 2425 rue de l’Agriculture, Québec City, Québec G1V 0A6, \\ Canada \\ ${ }^{\S}$ Institute of Nutrition and Functional Foods, Laval University, 2440 Boulevard Hochelaga, Québec City, Québec G1V 0A6, Canada \\ "Institut des Biomolécules Max Mousseron, UMR 5247-CNRS, Université de Montpellier, Faculté de Pharmacie, 15 Avenue Charles \\ Flahault, BP 14491 Montpellier Cedex 05, Montpellier, 34093, France
}

\begin{abstract}
This study assesses the effects of cyclic fatty acid monomers (CFAM) from heated vegetable oils on oxidative stress and inflammation. Wistar rats were fed either of these four diets for 28 days: canola oil (CO), canola oil and 0.5\% CFAM (CC), soybean oil (SO), and soybean oil and $0.5 \%$ CFAM (SC). Markers of oxidative stress and inflammation were determined by micro liquid chromatography tandem mass spectrometry (micro-LC-MS/MS) and enzyme-linked immunosorbent assay (ELISA) kits, respectively. Analysis of variance (ANOVA) for a $2 \times 2$ factorial design was performed to determine the CFAM and oil effects and interactions between these two factors at $P \leq 0.05$. For significant interactions, a post hoc multiple comparison test was performed, i.e., Tukey HSD (honest significant difference) test. CFAM induced higher plasma levels of 15$\mathrm{F}_{2 \mathrm{t}}$-IsoP (CC, $396 \pm 43 \mathrm{ng} / \mathrm{mL}, \mathrm{SC}, 465 \pm 75 \mathrm{ng} / \mathrm{mL}$ vs CO, $261 \pm 23 \mathrm{ng} / \mathrm{mL}$ and SO, $\left.288 \pm 35 \mathrm{ng} / \mathrm{mL}, P<0.05\right)$. Rats fed the SC diet had higher plasma 2,3-dinor-15- $\mathrm{F}_{2 \mathrm{t}}-\mathrm{IsoP}$ (SC, $145 \pm 9 \mathrm{ng} / \mathrm{mL}$ vs CC, $84 \pm 8 \mathrm{ng} / \mathrm{mL}, \mathrm{CO}, 12 \pm 1 \mathrm{ng} / \mathrm{mL}$, and SO, $12 \pm 1 \mathrm{ng} / \mathrm{mL}, P<0.05)$, urinary 2,3-dinor- $15-\mathrm{F}_{2 \mathrm{t}}$-IsoP $(\mathrm{SC}, 117 \pm 12 \mathrm{ng} / \mathrm{mL}$ vs CC, $67 \pm 13 \mathrm{ng} / \mathrm{mL}, \mathrm{CO}, 15 \pm 2 \mathrm{ng} / \mathrm{mL}$, and SO, $18 \pm 4 \mathrm{ng} / \mathrm{mL}, P<0.05)$, and plasma IL-6 (SC, $57 \pm 10 \mathrm{pg} / \mathrm{mL}$ vs CC, $48 \pm 11 \mathrm{pg} / \mathrm{mL}, \mathrm{CO}, 46 \pm 9 \mathrm{pg} / \mathrm{mL}$, and SO, $44 \pm$ $4 \mathrm{pg} / \mathrm{mL}, P<0.05)$ than the other three diet groups. These results indicate that CFAM increased the levels of markers of oxidative stress, and those effects are exacerbated by a CFAM-high-linoleic acid diet.
\end{abstract}

KEYWORDS: cyclic fatty acid monomers, soybean oil, canola oil, inflammation, oxidative stress

\section{INTRODUCTION}

Deep frying affects the quality of vegetable oils due to various chemical reaction products it generates, ${ }^{1,2}$ some of which may be undesired toxic compounds. ${ }^{3}$ The effects of some of the generated compounds have been studied. Mice fed a high-fat diet with polar compounds from deep-frying of palm oil displayed impaired liver function, lipid metabolism, and glucose tolerance. ${ }^{4}$ Cyclic fatty acid monomers (CFAM), present at relatively low levels ranging from 100 to $6600 \mathrm{mg}$ per $100 \mathrm{~g}$ of total fatty acids in commercial frying oils, ${ }^{5-9}$ increase liver triacylglycerols (TAG) and alter fatty acid synthesis and oxidation. ${ }^{8,9}$ Liver TAG accumulation is a complex phenomenon, ${ }^{10}$ as liver TAG synthesis can be protective $^{11}$ but can also trigger lipotoxicity and induce oxidative stress and inflammation. ${ }^{12,13}$ However, no study has endeavored to evaluate the relationship between dietary CFAM and oxidative stress and inflammation.

$\mathrm{F}_{2}$-isoprostanes $\left(\mathrm{F}_{2}\right.$-IsoP) are a class of prostaglandin-like compounds that are generated from arachidonic acid through nonenzymatic pathways, and they are considered the goldstandard marker for the quantification of in vivo oxidative stress in humans. ${ }^{14}$ Although $\mathrm{F}_{2}$-IsoP levels are not easily affected by dietary lipids, ${ }^{15}$ some compounds such as cocoa extract ${ }^{16}$ and some dietary fatty acids do affect the formation and excretion of $\mathrm{F}_{2}$-IsoP. Replacing a diet rich in saturated fatty acids (SFA) with linoleic acid, ${ }^{17}$ as well as replacing oleic acid with vaccenic acid, ${ }^{18}$ resulted in increased levels of $\mathrm{F}_{2}$-IsoP. In premenopausal women, a significant inverse association between levels of $\mathrm{F}_{2}$-IsoP and long-chain n-3 fatty acids was found, but trans fats were positively associated with $\mathrm{F}_{2}$-IsoP. ${ }^{19}$ A study among midlife women ${ }^{20}$ found that SFA, linoleic, and oleic acids are associated with high levels of markers of oxidative stress. Beside $\mathrm{F}_{2}$-IsoP, other oxidized lipids have been identified, such as $\mathrm{F}_{4 \mathrm{t}}$-neuroprostanes (NeuroP), which are generated from nonenzymatic oxidation of docosahexaenoic acid (DHA) and have been implicated in neurodegenerative conditions. $^{21}$ However, there is no study documenting the effects of CFAM from heated vegetable oils on markers of oxidative stress using liquid chromatography tandem mass spectrometry (LC-MS/MS).

The present study was designed to determine whether CFAM added to either canola oil (high-oleic) diet or soybean oil (high-linoleic) diet can increase the risk of oxidative stress in rats. In view of this objective, we evaluated concentrations of various markers of oxidative stress in the liver, plasma, and 
urine of an experimental dietary rat model and the concentrations of interleukin-6 (IL-6) and C-reactive protein (CRP), physiological markers of subclinical systemic inflammation in the plasma. ${ }^{22}$

\section{MATERIALS AND METHODS}

2.1. Chemicals. Methanol, acetonitrile, and chloroform (respectively, $\mathrm{MeOH}, \mathrm{ACN}$ LC-MS grade, and $\mathrm{CHCl}_{3} \mathrm{HPLC}$ grade) were purchased from Fisher Scientific U.K. (Loughborough, U.K.). Hexane HPLC grade and ethanol absolute LC-MS grade were purchased from Sigma-Aldrich (Saint Quentin Fallavier, France), whereas ethyl acetate (HPLC grade) was obtained from VWR (EC). Water $\left(\mathrm{H}_{2} \mathrm{O}\right)$ and isopropyl alcohol used in this study were of LC-MS grade. $\mathrm{KOH}$, formic acid, and $\mathrm{NH}_{4} \mathrm{OH} 28 \%$ were used in our experiments.

2.2. Standards. Standards used in this study are already described in a previous study by Dupuy et al. ${ }^{23}$ All the following standards were synthesized according to our published procedures: ${ }^{2,25}$ ent-16(RS)-9epi-ST- $\Delta^{14}$-10-PhytoF, ent-9(RS)-12-epi-ST- $\Delta^{14}-13$-PhytoF, ent-

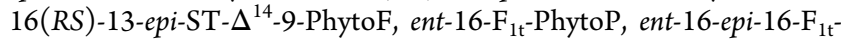

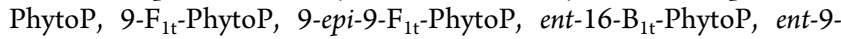
$\mathrm{L}_{1 \mathrm{t}}$-PhytoP, 16(RS)-16- $\mathrm{A}_{1 \mathrm{t}}$-PhytoP, 2,3-dinor-15- $\mathrm{F}_{2 \mathrm{t}}$-IsoP, 2,3-dinor15-epi-15- $\mathrm{F}_{2 \mathrm{t}}$-IsoP, ent-2,3-dinor-5,6-dihydro-dinor-15- $\mathrm{F}_{2 \mathrm{t}}$-IsoP, 15-

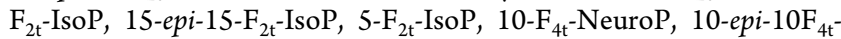
NeuroP, and $4(R S)-4-\mathrm{F}_{4 \mathrm{t}}$-NeuroP. Just as for our internal standards, these standards' purities were assessed by high-performance liquid chromatography (HPLC) and contained $<5 \%$ impurity.

2.3. Internal Standards. Of the three internal standards, $D_{4}-15-$ $\mathrm{F}_{2 \mathrm{t}}$ IsoP ( $\geq 98 \%$ purity) was purchased from Cayman Chemicals (Ann Arbor, MI, U.S.A.) and C21-15- $\mathrm{F}_{2 \mathrm{t}}$-IsoP and $\mathrm{D}_{4}$-epi-10- $\mathrm{F}_{4 \mathrm{t}}-\mathrm{NeuroP}$ were synthesized according to our published procedures, ${ }^{24,25}$ and both had less than $5 \%$ impurity content as confirmed by our HPLC analysis.

2.4. Animals and Diets. Thirty-six (36) male Wistar rats initially weighing ca. $150 \mathrm{~g}$ were acclimated to their new environment for 7 days and fed a rat chow (Purina Canada, Mississauga, ON). After acclimation, rats were housed in individual cages and randomly assigned one of the four diets groups and had a 7 day adaptation period followed by a 28 day experimental period. Twenty days through the experiment, rats were put in metabolic cages, and urine was collected every $6 \mathrm{~h}$ for $24 \mathrm{~h}$ in tubes that were immersed in ice. All the collections of the day were pooled, $50 \mu \mathrm{L}$ of butylated hydroxytoluene (BHT) $0.005 \%$ in methanol was added, and they were stored first at $-20^{\circ} \mathrm{C}$ and thereafter at $-80^{\circ} \mathrm{C}$ until analysis. At the end of the 28 day period, all animals were sacrificed by cardiac puncture under isoflurane USP (Pharmaceutical Partners Canada, Richmond Hill, ON), and plasma was recovered from whole blood after centrifugation $\left(2000 \mathrm{rpm}, 10 \mathrm{~min}\right.$, at $4{ }^{\circ} \mathrm{C}$ ) and stored immediately in liquid nitrogen and further at $-80^{\circ} \mathrm{C}$ until analysis.

Prior to the formulation of diets, CFAM were isolated from linseed oil heated at $275{ }^{\circ} \mathrm{C}$ for $12 \mathrm{~h}$ as previously described. ${ }^{26}$ Four purified diets were constituted as a combination of source of dietary fat $(10 \%$ canola oil or soybean oil) and the addition of CFAM ( $0.0 \%$ or $0.5 \%$ CFAM of total dietary fat): canola oil (CO), canola oil and CFAM (CC), soybean oil (SO), and soybean and CFAM (SC). Each of the four diets contained $18 \%$ protein (casein), $20 \%$ sucrose, $42 \%$ maize starch, $5 \%$ cellulose, $0.3 \%$ L-cysteine, $0.2 \%$ choline bitartrate, $1 \%$ vitamin mix (AIN-93-VX0), and 3.5\% mineral mix (AIN-93-MX). The four diets were isoenergetic (CO, $19.5 \mathrm{~kJ} / \mathrm{g} ; \mathrm{CC}, 19.4 \mathrm{~kJ} / \mathrm{g}$; SO, $19.5 \mathrm{~kJ} / \mathrm{g}$; SC, $19.5 \mathrm{~kJ} / \mathrm{g}$ ), isolipidic [CO, 19.3\% (w/w); CC, $19.3 \%$ $(\mathrm{w} / \mathrm{w}) ;$ SO, $18.9 \%(\mathrm{w} / \mathrm{w}) ; \mathrm{SC}, 19.7 \%(\mathrm{w} / \mathrm{w})]$, and isonitrogenous [CO, 10.1\% (w/w); CC, 10.3\% (w/w); SO, 10.0\% (w/w); SC, $10.2 \%$ $(\mathrm{w} / \mathrm{w})]$. Canola oil and soybean oil fatty acid profiles were as follows, respectively (wt \% of total fatty acids): saturated fatty acids or SFA (4.8 and 13.2), monounsaturated fatty acids or MUFA (61.3 and 20.5), linoleic acid or 18:2n-6 (17.8 and 52), $\alpha$-linolenic acid or $18: 3 n-3$ ( 8 and 6.7). The ratio of $n-6$ to $n-3$ was 2.2 for canola oil and 7.8 for soybean oil.
Treatment procedures and animal care were approved by the Laval University Animal Care Committee in accordance with the Canadian Council on Animal Care guidelines (file no. 2015-004).

2.5. Plasma Fatty Acid Analysis. Prior to fatty acid analysis, total lipids were extracted from $200 \mu \mathrm{L}$ of plasma according to Folch et al., 27 and fatty acids were analyzed with a gas chromatograph (Shimadzu GC-2010, Santa Clara, CA, U.S.A.) according to our methods as previously described. ${ }^{28}$

2.6. Extraction, Analysis, and Quantification of Nonenzymatic Lipid Products. For the analysis of F2-IsoP, we use LC-MS/MS, which is the most appropriate technique to determine $\mathrm{F}_{2}$-IsoP levels as immunoassay can generate artifactual issues. ${ }^{29}$ In all the extraction processes we used Oasis Max $(30 \mu \mathrm{m}, 60 \mathrm{mg})$ extraction plates (Waters, Milford, MA, U.S.A.) which were found to be suitable for LC-MS/MS per Dupuy et al. ${ }^{23}$

2.6.1. Extraction from Urine. 2.6.1.1. Sample Preparation. An amount of $1 \mathrm{~mL}$ of urine is placed in a Pyrex tube with $1 \mathrm{~mL}$ of formic acid $40 \mathrm{mM}(\mathrm{pH} 4.5)$ to homogenize the $\mathrm{pH}$ of the sample and $5 \mu \mathrm{L}$ of internal standards (5 ng). The mix is then vortexed.

2.6.1.2. Isoprostanes Extraction. The extraction begins with the conditioning of the solid-phase extraction (SPE) column with $2 \times 1$ $\mathrm{mL}$ of methanol and $2 \times 1 \mathrm{~mL}$ of formic acid $20 \mathrm{mM}$. After the column is conditioned, samples are charged on the column and the column is cleaned with $2 \times 1 \mathrm{~mL}$ of, respectively, $\mathrm{NH}_{3} 2 \%$, methanol/ formic acid $20 \mathrm{mM}(30: 70, \mathrm{v} / \mathrm{v})$, hexane, and hexane/ethyl acetate $(70: 30, \mathrm{v} / \mathrm{v})$. Isoprostanes are eluted with hexane/ethanol/acetic acid $(70: 29.4: 0.6, \mathrm{v} / \mathrm{v} / \mathrm{v})$. The solvent is then dried under a stream of nitrogen at $40{ }^{\circ} \mathrm{C}$ for $30 \mathrm{~min}$, and $100 \mu \mathrm{L}$ of mobile phase (water/ acetonitrile, $83: 17, \mathrm{v} / \mathrm{v}$, with each containing $0.1 \%$ formic acid) is added, the sample is vortexed, left for $15 \mathrm{~min}$, vortexed again, and 80 $\mu \mathrm{L}$ is placed in a vial for micro-LC-MS/MS analysis

2.6.2. Extraction from Plasma. Dupuy et al. noted that $\geq 200 \mu \mathrm{L}$ of mouse plasma was enough for the analysis of few isoprostanes. ${ }^{23}$ To get a broader profile of the nonenzymatic oxidized lipid products, we used $400 \mu \mathrm{L}$ of plasma. Prior to the isoprostanes extraction process, $400 \mu \mathrm{L}$ of rat plasma was placed in tubes for hydrolysis with $20 \mu \mathrm{L}$ of

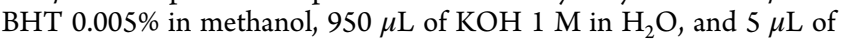
internal standards $(1 \mathrm{ng} / \mu \mathrm{L})$. The tubes were mounted on a mixer with a programmable mixing cycle (PTR-30, Grant-bio), and then placed in an incubator (IKA KS 4000i control) for $30 \mathrm{~min}$ at $40{ }^{\circ} \mathrm{C}$. After incubation, $1 \mathrm{~mL}$ of formic acid $40 \mathrm{mM}$ was added to each tube. Isoprostanes were then extracted as described in section 2.6.1.2.

2.6.3. Extraction from Liver. 2.6.3.1. Lipid Extraction. Prostanoids were extracted from ca. $200 \mathrm{mg}$ of liver in grinding matrix tubes (Lysing matrix D, MP Biochemicals, Illkirch, France) with $50 \mu \mathrm{L}$ of BHT $1 \%$ in methanol and $1 \mathrm{~mL}$ of methanol/water EGTA $5 \mathrm{mM}$ (2:1). Tubes were then placed in a FastPrep-24 (MP Biochemicals), and tissues were ground for $30 \mathrm{~s}$ at a speed of $6.5 \mathrm{~m} / \mathrm{s}$. Lipids were extracted as previously described. ${ }^{27}$ The ground tissue was transferred in centrifuge polypropylene tubes with $5 \mathrm{~mL}$ of chloroform/methanol (2:1), $1 \mathrm{~mL}$ of $\mathrm{NaCl} 0.9 \%$, and $5 \mu \mathrm{L}$ of internal standards $(1 \mathrm{ng} / \mu \mathrm{L})$, and the mixture was vortexed and centrifuged at $3500 \mathrm{rpm}$ for $10 \mathrm{~min}$ at room temperature. The organic phase was recovered in new Pyrex tubes, and the solvent was dried under a stream of nitrogen at $40{ }^{\circ} \mathrm{C}$ for about an hour and half.

2.6.4. Hydrolysis. Lipids were hydrolyzed with $1 \mathrm{~mL}$ of $\mathrm{KOH} 1 \mathrm{M}$ in methanol, in the same conditions as for plasma lipids. After hydrolysis, $2 \mathrm{~mL}$ of formic acid $40 \mathrm{mM}$ was added, and isoprostanes were extracted as described in section 2.6.1.2.

2.7. Analysis of Nonenzymatic Lipid Products by Micro-LCMS/MS. 2.7.1. LC Parameters. The analysis was conducted on an Eksigent (Sciex Applied Biosystems, Flamingham, MA, U.S.A.) microHPLC equipped with CTC Analytics AG (Zwingen, Switzerland) and coupled to a QTRAP 5500 system (AB SCIEX, Concord, ON, Canada). A HALO C18 column $(10 \mathrm{~mm} \times 0.5 \mathrm{~mm}, 2.7 \mu \mathrm{m}$, Eksigent, Dublin, CA, U.S.A.) was used for the micro-HPLC analysis. The LC mobile phase consisted of a mixture of solvents $\mathrm{A}\left(\mathrm{H}_{2} \mathrm{O}\right.$ added with $0.1 \%$ formic acid) and $\mathrm{B}(\mathrm{ACN} / \mathrm{MeOH}, 80: 20$, v/v added with $0.1 \%$ formic acid) delivered at $0.03 \mathrm{~mL} \cdot \mathrm{min}^{-1}$. The binary gradient is as follows: at time $0,83 \% \mathrm{~A}$ and $17 \% \mathrm{~B}$; at $9.5 \mathrm{~min}, 78 \% \mathrm{~A}$ and $22 \% \mathrm{~B}$; at 
Table 1. Standards Calibration Curves

\begin{tabular}{|c|c|c|c|}
\hline compd & linear regression & $r$ & $\mathrm{IS}^{a}$ \\
\hline ent-16(RS)-9-epi-ST- $\Delta^{14}-10-P h y t o F$ & $Y=3.08779 x$ & 0.99988 & $\mathrm{D}_{4}-10-\mathrm{F}_{4 \mathrm{t}}-\mathrm{NeuroP}$ \\
\hline ent-9(RS)-12-epi-ST- $\Delta^{14}-13-\mathrm{PhytoF}$ & $Y=0.98618 x$ & 0.99983 & $\mathrm{D}_{4}-10-\mathrm{F}_{4 \mathrm{t}}-\mathrm{NeuroP}$ \\
\hline ent-16(RS)-13-epi-ST- $\Delta^{14}-9-\mathrm{PhytoF}$ & $Y=3.07013 x$ & 0.99994 & $\mathrm{D}_{4}-10-\mathrm{F}_{4 \mathrm{t}}-\mathrm{NeuroP}$ \\
\hline ent-16- $\mathrm{F}_{1 \mathrm{t}}$-PhytoP & $Y=0.18298 x$ & 0.99982 & $\mathrm{D}_{4}-10-\mathrm{F}_{4 \mathrm{t}}-\mathrm{NeuroP}$ \\
\hline ent-16-epi-16- $\mathrm{F}_{1 \mathrm{t}}$-PhytoP & $Y=0.22860 x$ & 0.99985 & $\mathrm{D}_{4}-10-\mathrm{F}_{4 \mathrm{t}}-\mathrm{NeuroP}$ \\
\hline 9- $\mathrm{F}_{1 \mathrm{t}}$-PhytoP & $Y=1.07221 x$ & 0.99977 & $\mathrm{D}_{4}-10-\mathrm{F}_{4 \mathrm{t}}-\mathrm{NeuroP}$ \\
\hline 9-epi-9-F $\mathrm{F}_{1 \mathrm{t}}$-PhytoP & $Y=1.30677 x$ & 0.99976 & $\mathrm{D}_{4}-10-\mathrm{F}_{4 \mathrm{t}}-\mathrm{NeuroP}$ \\
\hline ent-16- $\mathrm{B}_{1 \mathrm{t}}-\mathrm{PhytoP}$ & $Y=2.94248 x$ & 0.99894 & $\mathrm{D}_{4}-10-\mathrm{F}_{4 \mathrm{t}}-\mathrm{NeuroP}$ \\
\hline ent-9- $\mathrm{L}_{1 \mathrm{t}}$-PhytoP & $Y=3.21413 x$ & 0.99931 & $\mathrm{D}_{4}-10-\mathrm{F}_{4 \mathrm{t}}-\mathrm{NeuroP}$ \\
\hline $16(R S)-16-\mathrm{A}_{1 \mathrm{t}}-\mathrm{PhytoP}$ & $Y=0.49741 x$ & 0.99970 & $\mathrm{D}_{4}-10-\mathrm{F}_{4 \mathrm{t}}-\mathrm{NeuroP}$ \\
\hline 2,3-dinor-15- $\mathrm{F}_{2 \mathrm{t}}$-IsoP & $Y=1.15680 x$ & 0.99991 & $\mathrm{D}_{4}-10-\mathrm{F}_{4 \mathrm{t}}-\mathrm{NeuroP}$ \\
\hline 2,3-dinor-15-epi-15- $\mathrm{F}_{2 \mathrm{t}}$-IsoP & $Y=0.90891 x$ & 0.99972 & $\mathrm{D}_{4}-10-\mathrm{F}_{4 \mathrm{t}}-\mathrm{NeuroP}$ \\
\hline ent-2,3-dinor-5,6-dihydro-dinor-15- $\mathrm{F}_{2 \mathrm{t}}$-IsoP & $Y=3.78958 x$ & 0.99974 & $\mathrm{D}_{4}-10-\mathrm{F}_{4 \mathrm{t}}-\mathrm{NeuroP}$ \\
\hline $15-\mathrm{F}_{2 \mathrm{t}} \mathrm{-IsoP}$ & $Y=0.24073 x$ & 0.99868 & $\mathrm{D}_{4}-10-\mathrm{F}_{4 \mathrm{t}}-\mathrm{NeuroP}$ \\
\hline 15-epi-15- $\mathrm{F}_{2 \mathrm{t}}$-IsoP & $Y=0.35380 x$ & 0.99983 & $\mathrm{D}_{4}-10-\mathrm{F}_{4 \mathrm{t}}$-NeuroP \\
\hline $5-\mathrm{F}_{2 \mathrm{t}}$-IsoP & $Y=0.21236 x$ & 0.99977 & $\mathrm{D}_{4}-10-\mathrm{F}_{4 \mathrm{t}}-\mathrm{NeuroP}$ \\
\hline $10-\mathrm{F}_{4 \mathrm{t}}-\mathrm{NeuroP}$ & $Y=0.96412 x$ & 0.99985 & $\mathrm{D}_{4}-10-\mathrm{F}_{4 \mathrm{t}}-\mathrm{NeuroP}$ \\
\hline 10-epi- $10 \mathrm{~F}_{4 \mathrm{t}}$-NeuroP & $Y=0.21099 x$ & 0.99968 & $\mathrm{D}_{4}-10-\mathrm{F}_{4 \mathrm{t}}-\mathrm{NeuroP}$ \\
\hline $4(R S)-4-\mathrm{F}_{4 \mathrm{t}}-\mathrm{NeuroP}$ & $Y=0.08500 x$ & 0.99816 & $\mathrm{D}_{4}-10-\mathrm{F}_{4 \mathrm{t}}-\mathrm{NeuroP}$ \\
\hline
\end{tabular}

$11.5 \mathrm{~min}, 70 \% \mathrm{~A}$ and $30 \% \mathrm{~B}$; at $15 \mathrm{~min}, 70 \% \mathrm{~A}$ and $30 \% \mathrm{~B}$, and then at $16 \mathrm{~min}, 5 \% \mathrm{~A}$ and $95 \% \mathrm{~B}$ for $2.3 \mathrm{~min}$, for a total run time of $21 \mathrm{~min}$. The sample injection volume was $5 \mu \mathrm{L}$.

2.7.2. MS/MS Conditions. The MS/MS was operated in the electrospray ionization (ESI) negative mode with a source voltage kept at $-4.5 \mathrm{kV}$ and $\mathrm{N}_{2}$ used as curtain gas. For each analyte, the collision energy was optimized to maximize the ion currents of the precursor to produce ion dissociation. The analytes were detected by MS/MS using multiple reaction monitoring (MRM). All the MRM for our analytes have already been reported by Dupuis et al. ${ }^{23}$

2.7.3. Quantification of Nonenzymatic Lipid Products. The quantitation of prostanoids was done with MultiQuant 3.0 software ( $A B$ SCIEX). Prior to the quantification, calibration curves were obtained from the ratio of the areas under the curves of isoprostanes and those of the internal standard (IS) as a function of the ratio of the concentration of isoprostanes and IS. The linear regressions obtained for all the standards are presented in Table 1 .

2.7.4. Extraction Yield and Matrix Effect. The yield gives the percentage of any given analyte recovered after SPE, while matrix effect refers to the difference in mass spectrometric response for analyte in standard solution versus the response of the same analyte in a biological matrix. Two concentrations of standards were used to calculate these two parameters: $32 \mathrm{pg} / \mu \mathrm{L}(\mathrm{C} 32)$ and $256 \mathrm{pg} / \mu \mathrm{L}$ (C256). For each concentration, duplicate samples were prepared before and after column extraction and a standard solution into starting mobile phase was also prepared and used as quality control. The yield for each concentration corresponds to the ratio between the area under the curve (AUC) of the analyte before and after extraction. The matrix effect is the ratio, for each concentration, between the AUC of any analyte after extraction and the AUC of the standard solution.

2.8. Statistical Analysis. All the results are expressed as mean \pm $\mathrm{SD}(n=9)$. Analysis of variance (ANOVA) for $2 \times 2$ factorial experimental design was performed with SAS software (SAS Institute Inc., Cary, NC, U.S.A.) to determine the CFAM and oil effects, as well as interactions among CFAM and dietary oils. For plasma IL-6, a logarithmic transformation of data was applied $\left[\log _{10}(x+1)\right]$ to achieve the homogeneity of variance. When significant interactions were observed between oil and CFAM, a multiple comparison test, i.e., Tukey honest significant difference (HSD) test, was used to determine differences between the groups. Pearson correlation coefficients were calculated between variables. The level of significance was set at $P \leq 0.05$.

\section{RESULTS}

3.1. Yield, Matrix Effect, and Repeatability and Precision of the Method. Yields and matrix effects are expressed as mean in $\% \pm \mathrm{SD} \%$ and presented in Table 2 .

Table 2. Summary Data for Isoprostanes and Neuroprostanes Yield and Matrix Effect

\begin{tabular}{|c|c|c|c|c|}
\hline \multirow[b]{2}{*}{$\operatorname{compd}^{a}$} & \multicolumn{2}{|c|}{ yield } & \multicolumn{2}{|c|}{ matrix effect } \\
\hline & mean $(\%)$ & SD\% & mean $(\%)$ & SD\% \\
\hline \multicolumn{5}{|c|}{ Liver } \\
\hline $\mathrm{D}_{4}-15-\mathrm{F}_{2 \mathrm{t}}$-IsoP (IS) & 84 & 9 & 75 & 2 \\
\hline $\mathrm{D}_{4}-10$-epi-F $\mathrm{F}_{4 \mathrm{t}}-\mathrm{NeuroP}$ (IS) & 64 & 18 & 72 & 1 \\
\hline $15-\mathrm{F}_{2 \mathrm{t}}$-IsoP & 100 & 5 & 85 & 2 \\
\hline 2,3-dinor-15- $\mathrm{F}_{2 \mathrm{t}}$-IsoP & 105 & 9 & 73 & 2 \\
\hline $4(R S)-\mathrm{F}_{4 \mathrm{t}}-\mathrm{NeuroP}$ & 103 & 8 & 56 & 7 \\
\hline \multicolumn{5}{|c|}{ Plasma } \\
\hline $\mathrm{D}_{4}-15-\mathrm{F}_{2 \mathrm{t}}$-IsoP (IS) & 75 & 8 & 59 & 5 \\
\hline $\mathrm{D}_{4}-10-$ epi- $\mathrm{F}_{4 \mathrm{t}}-\mathrm{NeuroP}$ (IS) & 100 & 7 & 70 & 4 \\
\hline $15-\mathrm{F}_{2 \mathrm{t}}-\mathrm{IsoP}$ & 79 & 5 & 68 & 3 \\
\hline 2,3-dinor-15- $\mathrm{F}_{2 \mathrm{t}}$-IsoP & 33 & 6 & 82 & 2 \\
\hline $4(R S)-\mathrm{F}_{4 \mathrm{t}}-$ NeuroP & 91 & 7 & 69 & 3 \\
\hline \multicolumn{5}{|c|}{ Urine } \\
\hline $\mathrm{D}_{4}-15-\mathrm{F}_{2 \mathrm{t}}$-IsoP (IS) & 90 & 4 & 104 & 9 \\
\hline $\mathrm{D}_{4}-10$-epi- $\mathrm{F}_{4 \mathrm{t}}-\mathrm{NeuroP}$ (IS) & 90 & 3 & 69 & 6 \\
\hline $15-\mathrm{F}_{2 \mathrm{t}}$-IsoP & 99 & 7 & 77 & 6 \\
\hline 2,3 -dinor- $15-\mathrm{F}_{2 \mathrm{t}}$-IsoP & 94 & 5 & 77 & 4 \\
\hline $4(R S)-\mathrm{F}_{4 \mathrm{t}}-\mathrm{NeuroP}$ & 101 & 7 & 66 & 7 \\
\hline
\end{tabular}

${ }^{a} \mathrm{IS}$, internal standard; IsoP, isoprostanes; NeuroP, neuroprostanes.

Extractions from urine had the highest yields and lowest variation compared to extractions from liver and plasma, suggesting a putative impact of the hydrolysis step on the extraction process. In order to determine the linear range in the quantification process, we used 15 concentrations ranging from $3.125 \times 10^{-3}$ to $512 \mathrm{pg} \cdot \mu \mathrm{L}^{-1}$ prepared in triplicate and injected. This allowed us to establish calibration curves and calculating the linear regression equation. The detector response was linear across the range tested. Limit of detection 
Table 3. Fatty Acid Composition (wt \%) in Total Plasma Lipids of Rats Fed Diets Containing Canola Oil (CO), Canola Oil and CFAM (CC), Soybean Oil (SO), and Soybean Oil and CFAM (SC) ${ }^{a}$

\begin{tabular}{|c|c|c|c|c|c|c|}
\hline \multirow[b]{2}{*}{ fatty acid ${ }^{b}$} & \multicolumn{4}{|c|}{ diet } & \multicolumn{2}{|c|}{$P$ values } \\
\hline & $\mathrm{CO}$ & $\mathrm{CC}$ & SO & $\mathrm{SC}$ & oil & $\mathrm{CFAM}^{c}$ \\
\hline $16: 19 \mathrm{c}$ & $1.8 \pm 0.3$ & $2.3 \pm 0.3$ & $1.7 \pm 0.3$ & $1.4 \pm 1.2$ & NS & NS \\
\hline 18:0 & $8.8 \pm 0.9$ & $10.0 \pm 1.5$ & $9.2 \pm 1.2$ & $9.0 \pm 1.8$ & NS & NS \\
\hline $18: 1(n-9)$ & $23.7 \pm 2$ & $23.9 \pm 1.8$ & $9.3 \pm 1.8$ & $10.7 \pm 2.0$ & $* *$ & NS \\
\hline $18: 1(n-7)$ & $2.0 \pm 0.3$ & $2.4 \pm 0.6$ & $1.9 \pm 0.3$ & $1.7 \pm 0.6$ & $*$ & NS \\
\hline $20: 1(n-9)$ & $3.4 \pm 0.6$ & $3.0 \pm 0.6$ & $2.9 \pm 0.6$ & $2.9 \pm 1.2$ & $*$ & NS \\
\hline $20: 4(n-6)$ & $16.5 \pm 3.0$ & $14.4 \pm 1.8$ & $20.9 \pm 2.7$ & $20.0 \pm 4.8$ & $*$ & NS \\
\hline $20: 5(n-3)$ & $1.4 \pm 0.6$ & $1.4 \pm 0.6$ & $0.8 \pm 0.18$ & $0.9 \pm 0.3$ & $*$ & NS \\
\hline $22: 5(n-6)$ & $2.4 \pm 0.6$ & $1.5 \pm 0.6$ & $2.8 \pm 0.9$ & $1.8 \pm 0.9$ & NS & $*$ \\
\hline $22: 6(n-3)$ & $3.2 \pm 1.2$ & $2.5 \pm 0.6$ & $5.3 \pm 1.8$ & $3.5 \pm 1.8$ & NS & * \\
\hline$\sum \mathrm{SFA}^{d}$ & $29.1 \pm 1.8$ & $29.0 \pm 2.1$ & $28.1 \pm 1.8$ & $29.6 \pm 2.4$ & NS & NS \\
\hline $\bar{\Sigma} \mathrm{MUFA}^{e}$ & $31.4 \pm 3.0$ & $33.3 \pm 3.0$ & $16.6 \pm 2.1$ & $17.4 \pm 2.7$ & $* *$ & NS \\
\hline$\sum$ PUFA n-3 ${ }^{f}$ & $8.4 \pm 1.8$ & $6.2 \pm 0.9$ & $10.4 \pm 2.1$ & $7.9 \pm 2.4$ & NS & $*$ \\
\hline $\bar{\sum} \mathrm{PUFA}^{g}$ & $37.1 \pm 3.0$ & $32.5 \pm 3.0$ & $50.3 \pm 3.0$ & $51.6 \pm 3.0$ & $* *$ & NS \\
\hline $22: 5 n-6 / 22: 6 n-3$ & $0.7 \pm 0.0$ & $0.5 \pm 0.0$ & $0.5 \pm 0.6$ & $0.5 \pm 0.0$ & NS & * \\
\hline
\end{tabular}

${ }^{a}$ Data are mean \pm SD (ANOVA, $P<0.05, n=9$ ). *, $P<0.05$; **, $P<0.01$; NS, not significant. ${ }^{b}$ Data for myristic, palmitic, palmitelaidic, linoleic, and $\alpha$-linolenic acids and total n-6 PUFA are presented in Figure 1. ${ }^{c}$ CFAM: cyclic fatty acid monomers. ${ }^{d}$ Sum of the saturated fatty acids. ${ }^{e}$ Sum of the monounsaturated fatty acids. ${ }^{f}$ Sum of the PUFA n-3. ${ }^{g}$ Sum of the total PUFA.
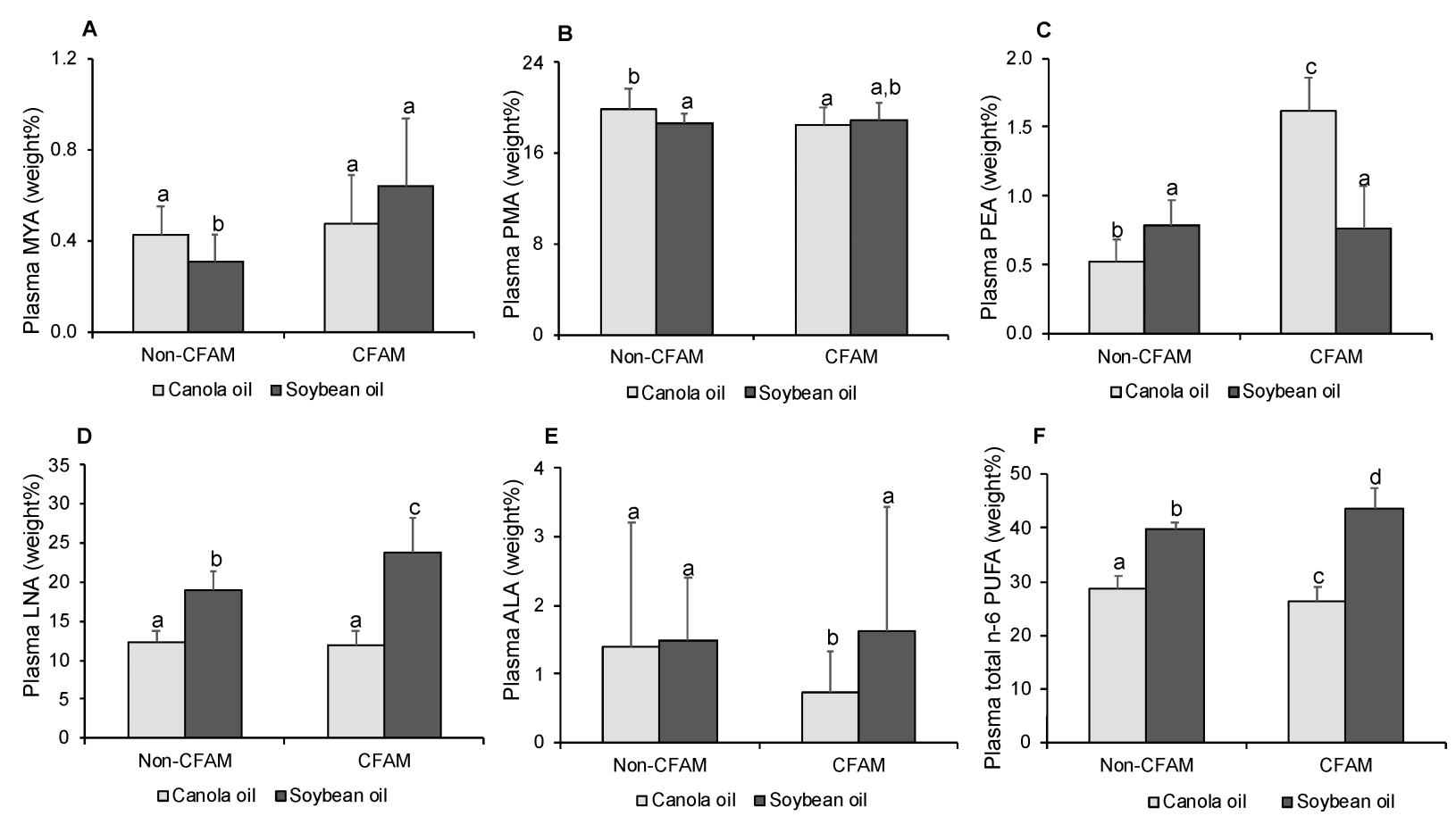

Figure 1. Effects of oil and CFAM on plasma myristic acid (MYA, A), palmitic acid (PMA, B), palmitelaidic acid (PEA, C), linoleic acid (LNA, D), $\alpha$-linolenic acid (ALA, E), and total n-6 polyunsaturated fatty acids (n-6 PUFA, F) of rats fed either canola oil or soybean oil with or without $0.5 \%$ of CFAM. Data are mean \pm SD. Data with different letter are significantly different [ANOVA followed by a post hoc Tukey honestly significant different (HSD) test, $P \leq 0.05, n=9]$.

(LOD) and limit of quantitation (LOQ) were also determined and ranged, respectively, from 0.16 to $0.63 \mathrm{pg}$ injected and between 0.16 and $1.25 \mathrm{pg}$ injected. These values depended on the type of isoprostanoids but were quite homogeneous.

3.2. Food Intake and Body Weight Gain. No changes were observed between the four diet groups for daily food intake or weight gain $(P>0.05)$.

3.3. Plasma Fatty Acid Composition. As per data presented in Table 3, canola oil induced higher plasma levels of oleic acid, total MUFA, and eicosapentaenoic acid (EPA) than soybean oil, and rats fed soybean oil had higher levels of plasma arachidonic acid (ARA) and total polyunsaturated fatty acids (PUFA) than canola oil $(P<0.05)$. The CFAM diets induced lower levels of DPAn-6, DHA, 22:5n-6/22:6n-3 ratio, and total n-3 PUFA than the non-CFAM diets $(P<0.05)$.

Dietary lipids modulated the effects of CFAM on six plasma fatty acids levels. Rats fed the soybean oil and CFAM (SC) diet had more linoleic acid (LNA) (Figure 1D) and PUFAn-6 (Figure 1F) than those fed the three other diets $(P<0.05)$. Rats fed the soybean oil (SO) diet had more LNA (Figure 1D) and PUFAn-6 (Figure 1F) than those fed the two canola oil diets, and less myristic acid (MYA) (Figure 1A) than the three 

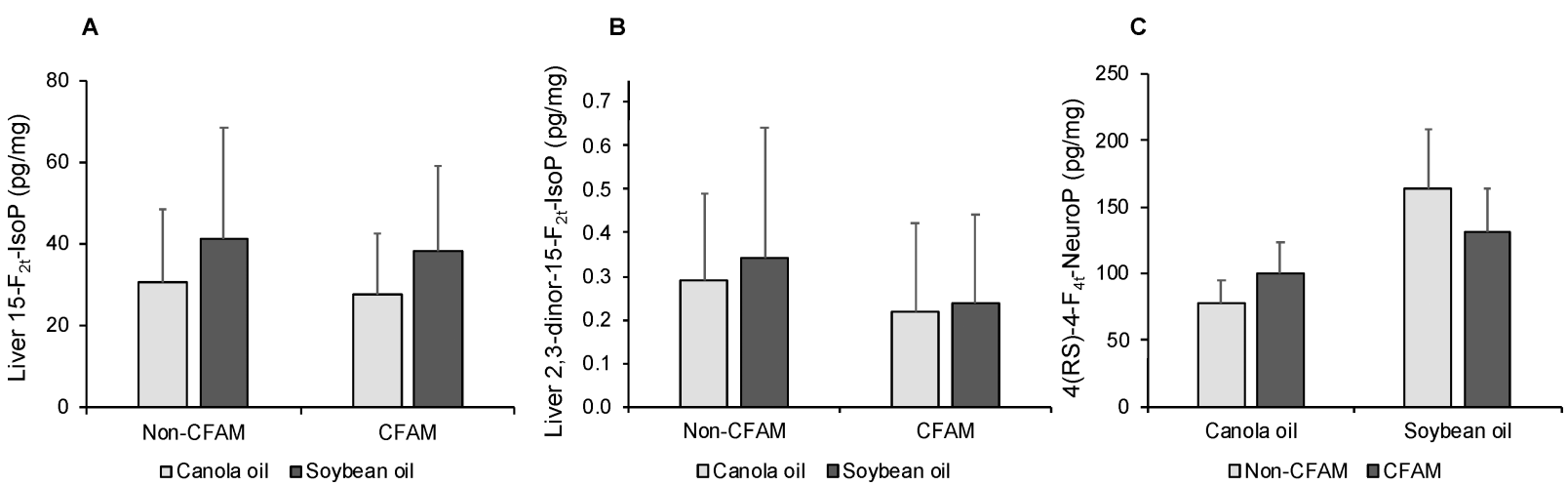

Figure 2. Liver 15-F2t-IsoP (A), 2,3-dinor-15- $\mathrm{F}_{2 \mathrm{t}}$-IsoP (B), and 4(RS)-4-F4t-NeuroP (C) of rats fed either canola oil or soybean oil with or without $0.5 \%$ of CFAM. Data are mean \pm SD (ANOVA, $P \leq 0.05, n=9)$.
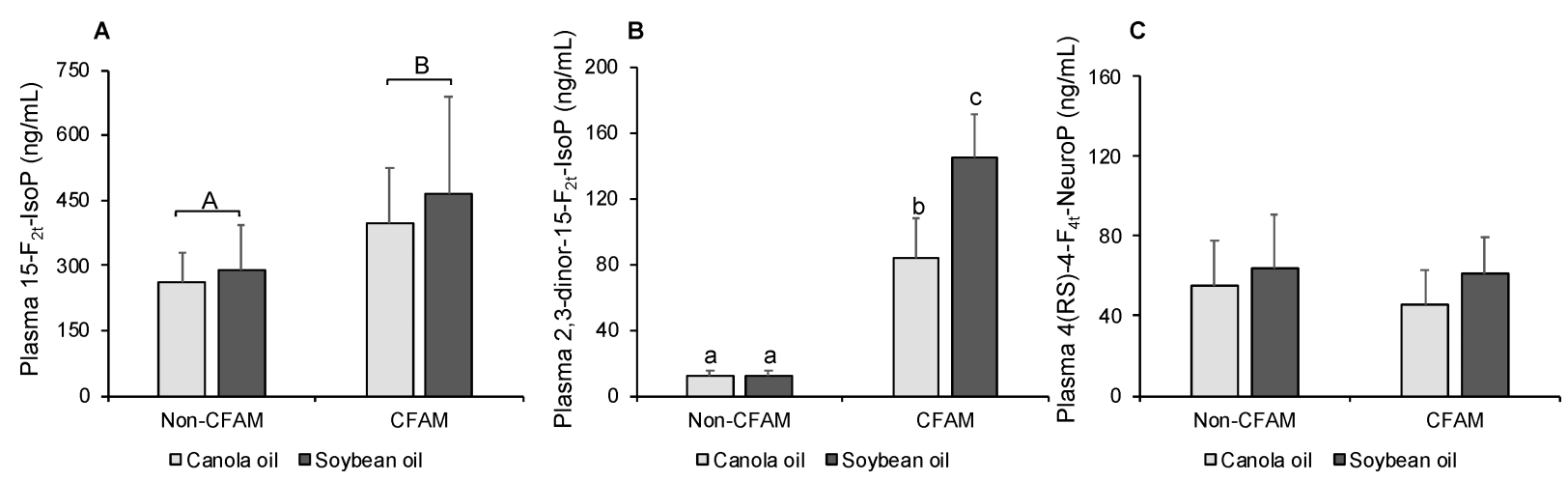

Figure 3. Plasma 15-F2t-IsoP (A), 2,3-dinor-15- $\mathrm{F}_{2 \mathrm{t}}$-IsoP (B), and 4(RS)-4-F4t-NeuroP (C) of rats fed either canola oil or soybean oil with or without $0.5 \%$ of CFAM. Data are mean \pm SD. Data with different letter superscripts are statistically different (ANOVA followed by a post hoc Tukey HSD test, $P \leq 0.05, n=9)$.
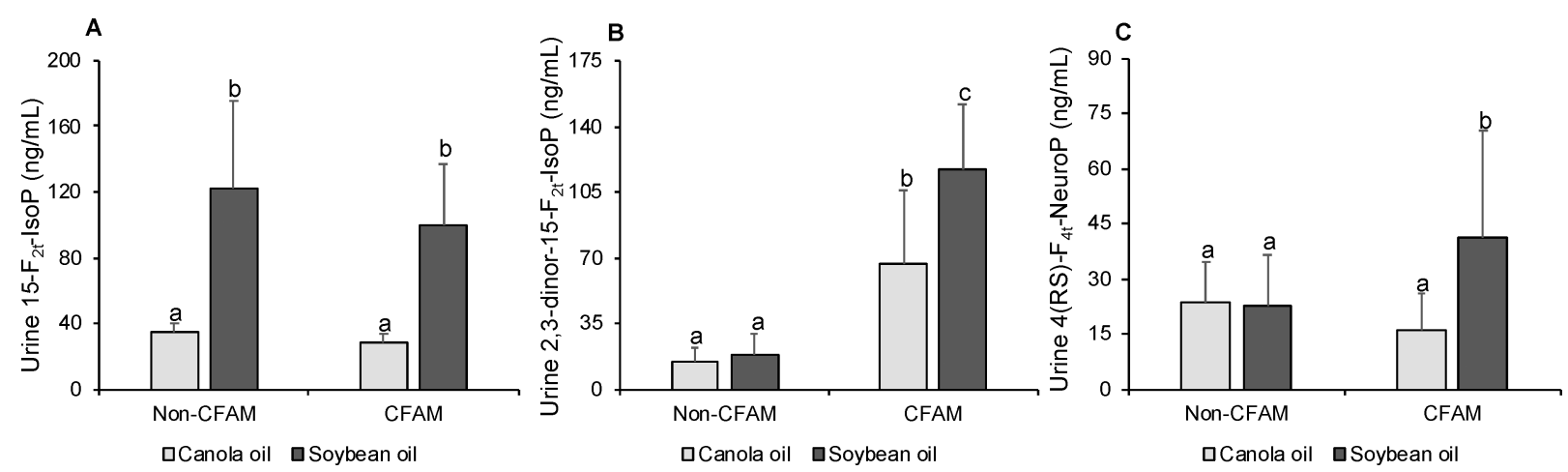

Figure 4. Urinary 15-F2t-IsoP (A), 2,3-dinor-15- $\mathrm{F}_{2 \mathrm{t}}$-IsoP (B), and 4(RS)-4-F4t-NeuroP (C) of rats fed either canola oil or soybean oil with or without $0.5 \%$ of CFAM. Data are mean \pm SD. Data with different letter superscripts are statistically different (ANOVA followed by a post hoc test Tukey HSD $P \leq 0.05, n=9)$.

other groups $(P<0.05)$. Rats fed the canola oil and CFAM diet (CC) had less $\alpha$-linolenic acid (ALA) (Figure 1E) and PUFAn-6 (Figure 1F) and more palmitelaidic acid (PEA) (Figure 1C) than those fed the three other diets $(P<0.05)$. Rats fed the CO diet had also more palmitic acid (PMA) (Figure 1B) than those fed the SO and CC diets. Plasma PEA levels (Figure 1C) were lower in the CO group compared with the three other groups.

3.4. Mediators of Oxidative Stress: Isoprostanes and Neuroprostanes. 3.4.1. Liver Isoprostanes and Neuroprostanes. Our results show that there was neither oil nor CFAM effect on liver $15-\mathrm{F}_{2 \mathrm{t}}$-IsoP (Figure $2 \mathrm{~A}$ ) and liver $4(R S)$ $\mathrm{F}_{4 \mathrm{t}}$-NeuroP (Figure 2C) $(P>0.05)$. However, rats fed CFAM tended $(P=0.053)$ to have lower 2,3-dinor-15- $\mathrm{F}_{2 \mathrm{t}}$-IsoP (Figure 2B) metabolite of $15-\mathrm{F}_{2 \mathrm{t}}$-IsoP, compared to those fed the non-CFAM diets.

3.4.2. Plasma Isoprostanes and Neuroprostanes. We observed a CFAM effect on plasma $15-\mathrm{F}_{2 \mathrm{t}}$-IsoP (Figure $3 \mathrm{~A}$ ), with the $\mathrm{CC}$ and $\mathrm{SC}$ diets inducing higher levels than the $\mathrm{CO}$ and SO diets $(P<0.05)$. There was a statistical interaction between oil and CFAM on plasma 2,3-dinor-15- $\mathrm{F}_{2 \mathrm{t}}$-IsoP (Figure 3B), with rats fed the SC diet having more than the other three diet groups $(P<0.05)$ and rats fed the $C C$ diet inducing more than those fed the $\mathrm{CO}$ and $\mathrm{SO}$ diets $(P<0.05)$. There was neither oil nor CFAM effect on plasma $4(R S)-\mathrm{F}_{4 \mathrm{t}^{-}}$ NeuroP $(P>0.05)$. 
A

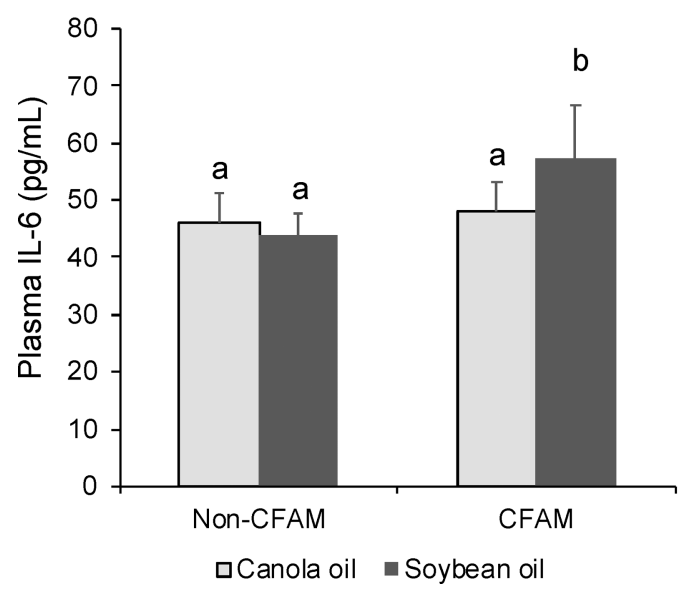

B

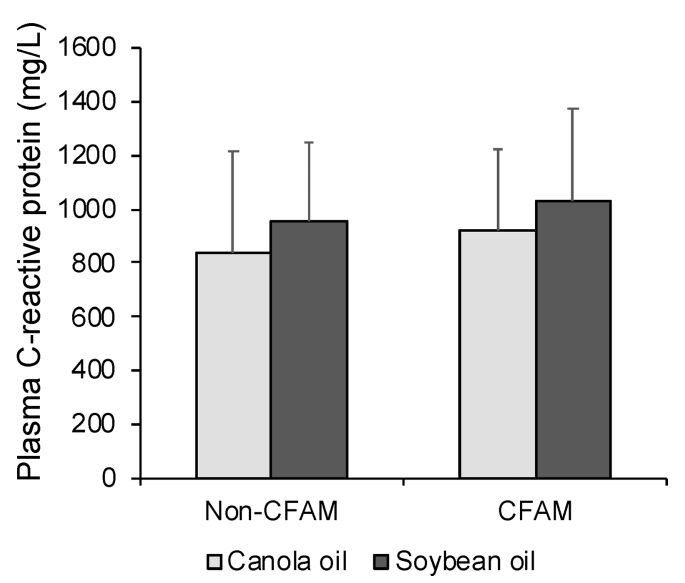

Figure 5. Plasma IL-6 and CRP of rats fed either canola oil or soybean oil with or without $0.5 \%$ of CFAM. Data are mean \pm SD. Data with different letter superscripts are statistically different (ANOVA followed by the post hoc Tukey HSD test, $P \leq 0.05, n=9$ ).

3.4.3. Urinary Isoprostanes and Neuroprostanes. We observed an oil effect on urinary $15-\mathrm{F}_{2 \mathrm{t}}$-IsoP (Figure $4 \mathrm{~A}$ ), rats fed soybean oil having higher levels than those fed canola oil $(P<0.05)$. We observed a statistical interaction between oil and CFAM on 2,3-dinor-15- $\mathrm{F}_{2 \mathrm{t}}$-IsoP (Figure $4 \mathrm{~B}$ ), showing that rats fed soybean oil and CFAM had more than those fed the three other diets and rats fed the canola oil and CFAM diet inducing more than those fed the $\mathrm{CO}$ and SO diets $(p<0.05)$. There was also a significant statistical interaction between oil and CFAM on $4(R S)-\mathrm{F}_{4 \mathrm{t}}-\mathrm{NeuroP}$ (Figure $4 \mathrm{C}$ ): rats fed the soybean oil and CFAM diet had higher levels compared to those fed one of the other three diet groups.

3.5. Inflammatory Markers. There was a significant statistical interaction between oil and CFAM on plasma IL-6 (Figure 5A), as rats fed soybean oil and CFAM had higher plasma levels compared to those fed either one of the other three diet groups $(P<0.05)$. We found no difference for plasma CRP (Figure 5B).

\section{DISCUSSION}

The present study aimed to assess the effects of CFAM on markers of inflammation and oxidative stress and to evaluate whether those effects can be modulated by dietary lipids. Our results showed that rats fed the soybean oil and CFAM (SC) diet had higher concentrations of LNA, PUFAn-6, and IL-6 in plasma as well as higher 2,3 -dinor- $15 \mathrm{~F}_{2 \mathrm{t}}$ - $\mathrm{IsoP}$ in plasma and urine and higher $4(R S)-\mathrm{F}_{4 \mathrm{t}}-\mathrm{NeuroP}$ in urine than those fed the three other diets $(P<0.05)$. To the best of our knowledge, this study is the first study to report deleterious effects of CFAM on markers of oxidative stress and inflammation when incorporated in a high-linoleic acid diet in rats.

4.1. Changes in Plasma Fatty Acids. Changes observed in plasma fatty acids among the four diet groups resulted either from oil and/or CFAM effect (Table 3) or from interactions between oil and CFAM (Figure 1). The high levels of linoleic acid (LNA, 18:2n-6) and $n-6 / n-3$ ratio (2.2 and 7.8, respectively, for dietary canola oil and soybean oil) may account for the high plasma $n-6 / n-3$ ratio and high concentrations of LNA and ARA and total n-6 PUFA found in rats fed soybean oil diet with or without CFAM. Dietary LNA can further be metabolized in many tissues by a series of desaturation and elongation steps to particularly ARA, and possibly docosapentaenoic acid (DPAn-6, 22:5n-6). These fatty acids serve as components of membrane structural lipids and are immediate precursors to eicosanoids and isoprostanes via enzymatic and nonenzymatic pathways, respectively. In addition, ARA is the most abundant PUFA in neural tissue and in the brain, ${ }^{30,31}$ and the role of ARA as an eicosanoid precursor is major in a variety of immune and inflammatory responses. ${ }^{32}$ High proportions of oleic acid found in plasma of rats fed canola oil compared to those fed soybean oil can have a dietary cause since canola oil diets contained roughly 3 times more oleic acid than soybean oil ( $61.3 \mathrm{wt} \%$ of total fatty acids for canola oil vs 20.5 for soybean oil). These results show that dietary lipids affect circulating fatty acid levels as previously reported. $^{33}$

DPAn- 6 and DHA are, respectively, the end products in the biosynthetic pathways of the n-6 and n-3 fatty acids, respectively, from LNA and $\alpha$-linolenic acid, and fatty acid desaturases (FADS), i.e., $\Delta-6$ and $\Delta-5$, are rate-limiting in those pathways. ${ }^{34}$ The lower levels of DPAn-6, DHA, and DPAn-6/DHA ratio in the plasma of rats fed the CFAM diets suggest some alteration of the biosynthetic pathways of those two fatty acids. It has been demonstrated that $\Delta-6$ desaturase (FADS2) is the rate-limiting enzyme for the conversion of linoleic acid and $\alpha$-linolenic acid to, respectively, $\gamma$-linolenic acid (18:3n-6) and stearidonic acid (18:4n-3). ${ }^{35,36}$ In fact, it has been found that trans fatty acids (TFA) and high cholesterol levels, among other factors, impair the activity of FADS2. Lower plasma levels of DPAn- 6 and DHA observed in this study suggest some similarities between CFAM and other products of thermo-oxidation of vegetable oils such as TFA on the biosynthetic pathways leading to DPA and DHA. Interestingly, there were $46.3 \%$ trans isomers in our CFAM fraction, but this study cannot determine whether the above effects were solely due to those trans isomers.

4.2. Soybean Oil Induces More Urinary $15-F_{2 t}-1$ soP than Canola Oil. The observation that soybean oil induced more urinary $15-\mathrm{F}_{2 \mathrm{t}}$-IsoP, a marker of oxidative stress, than canola oil is consistent with literature. Although isoprostanes were not measured in their study, Rom et al. ${ }^{37}$ found that soybean oil can induce oxidative stress by increasing lipid peroxides and stimulating macrophage foam cell formation. Our results are also in accord with those found by Gustafsson 
Table 4. Significant Correlations between Plasma IL-6, Fatty Acids, and Plasma and Urinary Isoprostanes $(P<0.05)^{a}$

\begin{tabular}{|c|c|c|c|c|c|}
\hline & plasma $15-F_{2 t}-I s o P$ & plasma 2,3-dinor-15- $\mathrm{F}_{2 \mathrm{t}}$-IsoP & urinary $15-\mathrm{F} 2 \mathrm{t}$-IsoP & urinary 2,3-dinor-15- $\mathrm{F}_{2 \mathrm{t}}$-IsoP & urinary $4(R S)-\mathrm{F}_{4 \mathrm{t}}$-NeuroP \\
\hline \multirow[t]{2}{*}{ IL-6 } & $r=0.47$ & $r=0.45$ & - & $r=0.47$ & $r=0.43$ \\
\hline & $P=0.004$ & $P=0.0062$ & & $P=0.0038$ & $P=0.009$ \\
\hline \multirow[t]{2}{*}{ oleic acid } & - & - & $r=-0.69$ & - & $r=-0.46$ \\
\hline & & & $P<0.0001$ & & $P=0.005$ \\
\hline \multirow[t]{2}{*}{ linoleic acid } & - & - & $r=0.51$ & - & $r=0.39$ \\
\hline & & & $P=0.0015$ & & $P=0.02$ \\
\hline \multirow[t]{2}{*}{ arachidonic acid } & - & - & $r=0.50$ & - & $r=0.44$ \\
\hline & & & $P=0.002$ & & $P=0.007$ \\
\hline
\end{tabular}

et al. ${ }^{38}$ who observed that, compared to soybean oil, canola oil increased $\gamma$-tocopherol, an antioxidant, in serum of hyperlipidemic subjects. Moreover, it has also been found that intakes of omega-6 polyunsaturated fatty acids (n-6 PUFA) higher than the median was associated with increased serum level of 8-isoprostane $\mathrm{F}_{2 \alpha}\left(15-\mathrm{F}_{2 \mathrm{t}}\right.$-IsoP) in subjects with type 2 diabetes mellitus with certain ApoA2 genotypes. ${ }^{39}$ Furthermore, a study found that rats fed an n-6 PUFA-rich oil had significantly reduced high-density lipoprotein (HDL)-cholesterol and high lipid peroxidation compared to those fed an n-3 PUFA-rich diet. ${ }^{40}$ Interestingly, we found higher levels of ARA-precursor to $15-\mathrm{F}_{2 \mathrm{t}}$ - IsoP-in rats fed soybean oil compared with those fed canola oil (Table 3), and there was a positive correlation between ARA and LNA and urinary 15$\mathrm{F}_{2 \mathrm{t}}$-IsoP (ARA, $r=0.50, P=0.002$; LNA, $r=0.51, P=0.001$ ). In contrast, plasma oleic acid (OLA), the major fatty acid in our canola oil, was negatively correlated with urinary $15-\mathrm{F}_{2 \mathrm{t}^{-}}$ IsoP $(r=-0.69, P<0.0001)$. Therefore, our results strongly suggest that soybean oil is a pro-oxidant oil as compared to canola oil.

4.3. CFAM Diets Induce More Plasma $15-F_{2 t}-I s o P$ than Non-CFAM Diets. Deep-fried oils have been reported to induce liver and serum lipid peroxidation in rats. ${ }^{41,42}$ Using cultured porcine endothelial cells, Flickinger et al. observed that CFAM-which are products of heat treatment of vegetable oils-increased the production and secretion of prostacyclin $\left(\mathrm{PGI}_{2}\right)$ which derives from ARA through the enzymatic cyclooxygenase pathway. ${ }^{43}$ Because $\mathrm{F}_{2}$-isoprostanes derive from ARA under oxidative stress conditions, our results on plasma $15-\mathrm{F}_{2 \mathrm{t}}$-IsoP suggest that CFAM may enhance the production of isoprostanes via a free radical nonenzymatic mechanism involving the peroxidation of ARA.

4.4. Soybean Oil and CFAM Diet Induces Higher Levels of Plasma and Urinary 2,3-Dinor-15- $F_{2 t}-I s o P$, Urinary 4(RS)-4- $\mathrm{F}_{4 \mathrm{t}}$-Neuroprostanes, and Plasma IL-6 than the Other Three Diets. The CFAM diets induced higher plasma levels of $15-\mathrm{F}_{2 \mathrm{t}}$-IsoP than the non-CFAM diets. Furthermore, the soybean and CFAM (SC) diet induced more plasma and urinary isoprostanes and plasma IL- 6 than the canola oil and CFAM (CC) diet. The elevated levels of 2,3dinor- $15-\mathrm{F}_{2 \mathrm{t}}$-IsoP, which is the metabolite of $15-\mathrm{F}_{2 \mathrm{t}}$-IsoP, in plasma and urine as well as $4(R S)-4-\mathrm{F}_{4 \mathrm{t}}-\mathrm{NeuroP}$ in urine of rats fed the SC diet indicate a general oxidative status which is associated with inflammation ${ }^{44}$ as evidenced by the positive correlations between plasma IL-6 and plasma and urinary 2,3dinor- $15-\mathrm{F}_{2 \mathrm{t}}$-IsoP $(r=0.45, P=0.006$ and $r=0.47, P=0.004$, respectively, Table 4 ). Thus, our results suggest that high levels of IL- 6 observed in the plasma of rats fed the SC diet resulted from a combination of factors related to dietary and plasma fats: First, rats fed the SC diet had high levels of LNA, and some oxidized forms of LNA such as 9-HODE are known to have pro-inflammatory properties. ${ }^{45}$ Second, rats fed the soybean oil diets had high levels of ARA and its nonenzymatic oxidized metabolites, i.e., plasma and urinary $15-\mathrm{F}_{2 \mathrm{t}}$-IsoP and 2,3-dinor-15- $\mathrm{F}_{2 \mathrm{t}}$-IsoP, than those fed the canola oil diets. Third, rats fed CFAM diets had lower levels of DPAn-6 and DHA (Table 3) than those fed non-CFAM diets. DPAn-6 reduces the activity of cyclooxygenase-2 (COX-2) and is a potent inhibitor of pro-inflammatory $\mathrm{PGE}_{2}$ production and, when combined with DHA, DPA-n-6 enhances the antiinflammatory activity of DHA. ${ }^{46,47}$ Therefore, our results strongly suggest that CFAM amplify the pro-oxidant and proinflammatory effect of soybean oil and might greatly account for the high levels of 2,3-dinor-15- $\mathrm{F}_{2}$-IsoP and IL-6 in plasma of rats fed soybean oil and CFAM diet.

Our results show that CFAM are associated with increased production of markers of oxidative stress in vivo and this effect is exacerbated when CFAM are supplemented with a n-6 PUFA-rich diet. On a nutritional level, this observation reinforces the need for a better selection of vegetable oils for frying, favoring oils with lower PUFA content.

\section{AUTHOR INFORMATION}

\section{Corresponding Author}

*Phone: +1 418 656-2131, ext 3864. Fax: +1 418 656-3353. Email: Helene.Jacques@fsaa.ulaval.ca.

\section{ORCID $\odot$}

Jean Mboma: 0000-0002-0486-7782

Camille Oger: 0000-0002-5177-5792

\section{Funding}

This study was supported by the Natural Sciences and Engineering Research Council of Canada (NSERC).

\section{Notes}

Parts of this work were presented at the American Oil Chemists' Society (AOCS) Latin American Congress and Exhibition on Fats, Oils, and Lipids, Cancun, Mexico, September 11-14, 2017.

The authors declare no competing financial interest.

\section{ACKNOWLEDGMENTS}

We would like to thank Antoine Godin and Charlène Marcotte for their help in animal experiment and results recording.

\section{ABBREVIATIONS USED}

CFAM, cyclic fatty acid monomers; DHA, docosahexaenoic acid; DPA, docosapentaenoic acid; LNA, linoleic acid; ARA, arachidonic acid; OLA, oleic acid; PUFA, polyunsaturated fatty acid; SFA, saturated fatty acid; TFA, trans fatty acid; IL-6, interleukin-6; CRP, C-reactive protein; IsoP, isoprostane; 
NeuroP, neuroprostanes; FADS, fatty acid desaturase; CO, canola oil; CC, canola oil and CFAM; SO, soybean oil; SC, soybean oil and CFAM; LC-MS/MS, liquid chromatography tandem mass spectrometry

\section{REFERENCES}

(1) Choe, E.; Min, D. B. Chemistry of deep-fat frying oils. J. Food Sci. 2007, 72 (5), R77-86.

(2) Gertz, C. Fundamentals of the frying process. Eur. J. Lipid Sci. Technol. 2014, 116 (6), 669-674.

(3) Thurer, A.; Granvogl, M. Generation of Desired Aroma-Active as Well as Undesired Toxicologically Relevant Compounds during Deep-Frying of Potatoes with Different Edible Vegetable Fats and Oils. J. Agric. Food Chem. 2016, 64 (47), 9107-9115.

(4) Li, X.; Yu, X.; Sun, D.; Li, J.; Wang, Y.; Cao, P.; Liu, Y. Effects of Polar Compounds Generated from the Deep-Frying Process of Palm Oil on Lipid Metabolism and Glucose Tolerance in Kunming Mice. J. Agric. Food Chem. 2017, 65 (1), 208-215.

(5) Frankel, E. N.; Smith, L. M.; Hamblin, C. L.; Creveling, R. K.; Clifford, A. J. Occurrence of cyclic fatty acid monomers in frying oils used for fast foods. J. Am. Oil Chem. Soc. 1984, 61 (1), 87-90.

(6) Gere, A.; Sebedio, J. L.; Grandgirard, A. Studies on some Hungarian fats and oils obtained from commercial frying processes. Fette, Seifen, Anstrichm. 1985, 87 (9), 359-362.

(7) Sebedio, J. L.; Grandgirard, A.; Septier, C.; Prevost, J. Chemical analyses of some frying oils obtained from restaurants. Rev. Fr. Corps Gras 1987, 34, 15-18.

(8) Lamboni, C.; Sebedio, J. L.; Perkins, E. G. Cyclic fatty acid monomers from dietary heated fats affect rat liver enzyme activity. Lipids 1998, 33 (7), 675-81.

(9) Martin, J. C.; Joffre, F.; Siess, M. H.; Vernevaut, M. F.; Collenot, P.; Genty, M.; Sebedio, J. L. Cyclic fatty acid monomers from heated oil modify the activities of lipid synthesizing and oxidizing enzymes in rat liver. J. Nutr. 2000, 130 (6), 1524-30.

(10) Trauner, M.; Arrese, M.; Wagner, M. Fatty liver and lipotoxicity. Biochim. Biophys. Acta, Mol. Cell Biol. Lipids 2010, 1801 (3), 299-310.

(11) Baskin-Bey, E. S.; Anan, A.; Isomoto, H.; Bronk, S. F.; Gores, G. J. Constitutive androstane receptor agonist, TCРОВOP, attenuates steatohepatitis in the methionine choline-deficient diet-fed mouse. World J. Gastroenterol. 2007, 13 (42), 5635-5641.

(12) Schaffer, J. E. Lipotoxicity: when tissues overeat. Curr. Opin. Lipidol. 2003, 14 (3), 281-7.

(13) Malhi, H.; Gores, G. J. Molecular mechanisms of lipotoxicity in nonalcoholic fatty liver disease. Semin. Liver Dis. 2008, 28 (4), 360-9.

(14) Roberts, L. J.; Morrow, J. D. Measurement of F2-isoprostanes: a reliable index of oxidant stress in vivo. Free Radical Biol. Med. 2000, 28 (4), 505-513.

(15) Gopaul, N. K.; Halliwell, B.; Anggard, E. E. Measurement of plasma F2-isoprostanes as an index of lipid peroxidation does not appear to be confounded by diet. Free Radical Res. 2000, 33 (2), 11527.

(16) Jalil, A. M.; Ismail, A.; Pei, C. P.; Hamid, M.; Kamaruddin, S. $\mathrm{H}$. Effects of cocoa extract on glucometabolism, oxidative stress, and antioxidant enzymes in obese-diabetic (Ob-db) rats. J. Agric. Food Chem. 2008, 56 (17), 7877-84.

(17) Sodergren, E.; Gustafsson, I. B.; Basu, S.; Nourooz-Zadeh, J.; Nalsen, C.; Turpeinen, A.; Berglund, L.; Vessby, B. A diet containing rapeseed oil-based fats does not increase lipid peroxidation in humans when compared to a diet rich in saturated fatty acids. Eur. J. Clin. Nutr. 2001, 55 (11), 922-31.

(18) Turpeinen, A. M.; Mutanen, M.; Aro, A.; Salminen, I.; Basu, S.; Palmquist, D. L.; Griinari, J. M. Bioconversion of vaccenic acid to conjugated linoleic acid in humans. Am. J. Clin. Nutr. 2002, 76 (3), 504-10.

(19) Anderson, C.; Milne, G. L.; Sandler, D. P.; Nichols, H. B. Oxidative stress in relation to diet and physical activity among premenopausal women. Br. J. Nutr. 2016, 116 (8), 1416-1424.
(20) Tomey, K. M.; Sowers, M. R.; Li, X.; McConnell, D. S.; Crawford, S.; Gold, E. B.; Lasley, B.; Randolph, J. F., Jr. Dietary fat subgroups, zinc, and vegetable components are related to urine F2aisoprostane concentration, a measure of oxidative stress, in midlife women. J. Nutr. 2007, 137 (11), 2412-9.

(21) Signorini, C.; De Felice, C.; Durand, T.; Oger, C.; Galano, J. M.; Leoncini, S.; Pecorelli, A.; Valacchi, G.; Ciccoli, L.; Hayek, J. Isoprostanes and 4-hydroxy-2-nonenal: markers or mediators of disease? Focus on Rett syndrome as a model of autism spectrum disorder. Oxid. Med. Cell. Longevity 2013, 2013, 343824.

(22) Pradhan, A. D.; Manson, J. E.; Rifai, N.; Buring, J. E.; Ridker, P. M. C-reactive protein, interleukin 6 , and risk of developing type 2 diabetes mellitus. JAMA 2001, 286 (3), 327-334.

(23) Dupuy, A.; Le Faouder, P.; Vigor, C.; Oger, C.; Galano, J. M.; Dray, C.; Lee, J. C.; Valet, P.; Gladine, C.; Durand, T.; BertrandMichel, J. Simultaneous quantitative profiling of 20 isoprostanoids from omega- 3 and omega- 6 polyunsaturated fatty acids by LC-MS/ MS in various biological samples. Anal. Chim. Acta 2016, 921, 46-58.

(24) Guy, A.; Oger, C.; Heppekausen, J.; Signorini, C.; De Felice, C.; Furstner, A.; Durand, T.; Galano, J. M. Oxygenated metabolites of n-3 polyunsaturated fatty acids as potential oxidative stress biomarkers: total synthesis of 8-F3t-IsoP, 10-F4t-NeuroP and [D4]-10-F4tNeuroP. Chem. - Eur. J. 2014, 20 (21), 6374-80.

(25) Oger, C.; Bultel-Ponce, V.; Guy, A.; Balas, L.; Rossi, J. C.; Durand, T.; Galano, J. M. The handy use of Brown's P2-Ni catalyst for a skipped diyne deuteration: application to the synthesis of a [D4]-labeled F4t-neuroprostane. Chem. - Eur. J. 2010, 16 (47), 13976-80.

(26) Sebedio, J. L.; Grandgirard, A. Cyclic fatty acids: natural sources, formation during heat treatment, synthesis and biological properties. Prog. Lipid Res. 1989, 28 (4), 303-36.

(27) Folch, J.; Lees, M.; Sloane Stanley, G. H. A simple method for the isolation and purification of total lipides from animal tissues. $J$. Biol. Chem. 1957, 226 (1), 497-509.

(28) Desmarais, A.; Pujos-Guillot, E.; Lyan, B.; Martin, J. F.; Leblanc, N.; Angers, P.; Sebedio, J. L. Cyclic fatty acids found in frying oils are detoxified via classical drug metabolic pathway but also by beta-oxidation and eliminated as conjugates in rats. Lipids 2015, 50 (4), 381-96.

(29) Halliwell, B.; Lee, C. Y. Using isoprostanes as biomarkers of oxidative stress: some rarely considered issues. Antioxid. Redox Signaling 2010, 13 (2), 145-56.

(30) Brenna, J. T.; Diau, G. Y. The influence of dietary docosahexaenoic acid and arachidonic acid on central nervous system polyunsaturated fatty acid composition. Prostaglandins, Leukotrienes Essent. Fatty Acids 2007, 77 (5-6), 247-50.

(31) Dyall, S. C. Long-chain omega-3 fatty acids and the brain: a review of the independent and shared effects of EPA, DPA, and DHA. Front. Aging Neurosci. 2015, 7, 52.

(32) Meng, H.; Liu, Y.; Lai, L. Diverse ways of perturbing the human arachidonic acid metabolic network to control inflammation. Acc. Chem. Res. 2015, 48 (8), 2242-50.

(33) Liao, F. H.; Liou, T. H.; Shieh, M. J.; Chien, Y. W. Effects of different ratios of monounsaturated and polyunsaturated fatty acids to saturated fatty acids on regulating body fat deposition in hamsters. Nutrition 2010, 26 (7-8), 811-7.

(34) Mathias, R. A.; Fu, W.; Akey, J. M.; Ainsworth, H. C.; Torgerson, D. G.; Ruczinski, I.; Sergeant, S.; Barnes, K. C.; Chilton, F. $\mathrm{H}$. Adaptive evolution of the FADS gene cluster within Africa. PLoS One 2012, 7 (9), e44926.

(35) Stoffel, W.; Hammels, I.; Jenke, B.; Binczek, E.; Schmidt-Soltau, I.; Brodesser, S.; Odenthal, M.; Thevis, M. Obesity resistance and deregulation of lipogenesis in Delta6-fatty acid desaturase (FADS2) deficiency. EMBO Rep. 2014, 15 (1), 110-20.

(36) Stoffel, W.; Holz, B.; Jenke, B.; Binczek, E.; Gunter, R. H.; Kiss, C.; Karakesisoglou, I.; Thevis, M.; Weber, A. A.; Arnhold, S.; Addicks, K. Delta6-desaturase (FADS2) deficiency unveils the role of omega3and omega6-polyunsaturated fatty acids. EMBO J. 2008, 27 (17), 2281-92. 
(37) Rom, O.; Jeries, H.; Hayek, T.; Aviram, M. Supplementation with linoleic acid-rich soybean oil stimulates macrophage foam cell formation via increased oxidative stress and diacylglycerol acyltransferase1-mediated triglyceride biosynthesis. Biofactors 2017, 43 (1), $100-116$.

(38) Gustafsson, I. B.; Vessby, B.; Ohrvall, M.; Nydahl, M. A diet rich in monounsaturated rapeseed oil reduces the lipoprotein cholesterol concentration and increases the relative content of n-3 fatty acids in serum in hyperlipidemic subjects. Am. J. Clin. Nutr. 1994, 59 (3), 667-74.

(39) Zamani, E.; Sadrzadeh-Yeganeh, H.; Sotoudeh, G.; Keramat, L.; Eshraghian, M.; Rafiee, M.; Koohdani, F. The interaction between ApoA2 $-265 \mathrm{~T}>\mathrm{C}$ polymorphism and dietary fatty acids intake on oxidative stress in patients with type 2 diabetes mellitus. Eur. J. Nutr. 2017, 56 (5), 1931-1938.

(40) Benson, M. K.; Devi, K. Influence of omega-6/omega-3 rich dietary oils on lipid profile and antioxidant enzymes in normal and stressed rats. Indian J. Exp. Biol. 2009, 47 (2), 98-103.

(41) Eder, K. The effects of a dietary oxidized oil on lipid metabolism in rats. Lipids 1999, 34 (7), 717-25.

(42) Garrido-Polonio, C.; Garcia-Linares, M. C.; Garcia-Arias, M. T.; Lopez-Varela, S.; Garcia-Fernandez, M. C.; Terpstra, A. H. M.; Sanchez-Muniz, F. J. Thermally oxidised sunflower-seed oil increases liver and serum peroxidation and modifies lipoprotein composition in rats. Br. J. Nutr. 2004, 92 (2), 257.

(43) Flickinger, B. D.; McCusker, R. H., Jr.; Perkins, E. G. The effects of cyclic fatty acid monomers on cultured porcine endothelial cells. Lipids 1997, 32 (9), 925-33.

(44) Wood, L. G.; Garg, M. L.; Simpson, J. L.; Mori, T. A.; Croft, K. D.; Wark, P. A.; Gibson, P. G. Induced sputum 8-isoprostane concentrations in inflammatory airway diseases. Am. J. Respir. Crit. Care Med. 2005, 171 (5), 426-30.

(45) Ramsden, C. E.; Zamora, D.; Leelarthaepin, B.; MajchrzakHong, S. F.; Faurot, K. R.; Suchindran, C. M.; Ringel, A.; Davis, J. M.; Hibbeln, J. R. Use of dietary linoleic acid for secondary prevention of coronary heart disease and death: evaluation of recovered data from the Sydney Diet Heart Study and updated meta-analysis. BMJ. 2013, 346, e8707.

(46) Nauroth, J. M.; Liu, Y. C.; Van Elswyk, M.; Bell, R.; Hall, E. B.; Chung, G.; Arterburn, L. M. Docosahexaenoic acid (DHA) and docosapentaenoic acid (DPAn-6) algal oils reduce inflammatory mediators in human peripheral mononuclear cells in vitro and paw edema in vivo. Lipids 2010, 45 (5), 375-84.

(47) Zhang, K.; Li, H.; Chen, W.; Zhao, M.; Cui, H.; Min, Q.; Wang, H.; Chen, S.; Li, D. Regulation of the Docosapentaenoic Acid/ Docosahexaenoic Acid Ratio (DPA/DHA Ratio) in Schizochytrium limacinum B4D1. Appl. Biochem. Biotechnol. 2017, 182 (1), 67-81. 